\title{
KONTRIBUSI MOTOR ABILITY DAN KONSENTRASI TERHADAP KEMAMPUAN PENGUASAAN KATA HEIAN YODAN KARATEKA LEMKARI DOJO ANGKASA LANUD PADANG
}

\author{
Arie Asnaldi \\ Jurusan Pendidikan Olahraga Prodi. Pendidikan Jasmani Kesehatan dan Rekreasi Fakultas Ilmu \\ Keolahragaan. Jalan Prof. Dr. Hamka Air Tawar Barat, Padang 25132, Indonesia Universitas Negeri \\ Padang \\ E-Mail: asnaldi@fik.unp.ac.id
}

\begin{abstract}
ABSTRAK
Permasalahan dalam penelitian ini berdasarkan pengamatan di lapangan, masih kurangnya beberapa aspek kondisi fisik yang mempengaruhi kata heian yodan yang dilakukan oleh karateka Lemkari Dojo Angkasa Lanud Padang. Di duga ada beberapa faktor yang mempengaruhi kata heian yodan, diantara faktor tersebut adalah motor ability dan konsentrasi. Penelitian ini bertujuan untuk menjelaskan kontribusi motor ability dan konsentrasi terhadap penguasaan kata heian yodan.

Metode penelitian ini adalah metode kuantitatif dengan menggunakan teknik analisis data regresi dan korelasi, baik tunggal maupun ganda. Populasi dalam penelitian ini adalah karateka Lemkari Dojo Angkasa Lanud Padang yang terdaftar dalam latihan, berjumlah 52 orang, dengan sampel sebanyak 32 orang yang di ambil secara purposive sampling yaitu karateka putri saja. Pengukuran data motor ability menggunakan Barrow Motor Ability Test yang selanjutnya diolah menggunakan rumus lewis, untuk data konsentrasi menggunakan Grid Concentration Test. Untuk pegukuran data penguasaan kata heian yodan dengan Rule Of Competition World Karate Federation dari Pengurus Besar FORKI dengan Kata Scoring Form dari Panduan Pertandingan FKTI-INKAI.

Dari analisis data diperoleh hasil: (1) Komponen motor ability memberikan kontribusi sebesar $17,39 \%$ terhadap penguasaan kata heian yodan; (2) Komponen konsentrasi memberikan kontribusi sebesar $12,47 \%$ terhadap penguasaan kata heian yodan; (3) Secara bersama-sama motor ability dan konsentrasi memberikan kontribusi sebesar $25,17 \%$ terhadap penguasaan kata heian yodan, dan persentase selebihnya di pengaruhi oleh faktor-faktor lain. Berdasarkan hasil penelitian tersebut, dapat disimpulkan bahwa motor ability dan konsentrasi memberikan kontribusi secara bersama-sama terhadap penguasaan kata heian yodan.

Kata Kunci: Motor Ability, Karate
\end{abstract}

\section{MOTOR ABILITY CONTRIBUTION AND CONCENTRATION ON HEIAN YODAN KARATEKA'S MASTERY ABILITY LEMKARI DOJO ANGKASA LANUD PADANG}

\begin{abstract}
The problem in this research is based on observations in the field, there is still a lack of some aspects of the physical conditions that affect the Heian said yodan conducted by karate dojo LEMKARI Space Lanud Padang. Presumably there are several factors that affect the Kata heian yodan, among these factors is the motor ability and concentration. This study aims to explain the contribution of the motor ability and concentration on the mastery of the Kata heian yodan.

This research method is quantitative method using data analysis techniques regression and correlation, either single or double. The population in this study is the karateka LEMKARI Dojo Space Lanud Padang enrolled in training, totaling 52 people, with a sample of 32 people were taken by purposive sampling that karateka daughter alone. Measurements ability using Barrow motor data Motor Ability Test were then processed using the formula lewis, to the concentration data using Grid Concentration Test. For mastery of data pegukuran Kata Heian yodan with Rule Of Competition World Karate Federation of the Executive Board of Forki with Kata Scoring Form of Free Game FKTI-INKAI.

Based on data analysis results: (1) The components of motor abilities contributed $17.39 \%$ to the mastery of the kata heian yodan; (2) Components of concentration contributed $12.47 \%$ to the
\end{abstract}


mastery of the word kata heian yodan; (3) Taken together the motor ability and concentration contributed $25.17 \%$ to the Heian yodan word mastery, and the remaining percentage is influenced by other factors. Based on these results, we can conclude that the motor ability and concentration to contribute jointly towards mastery of the kata heian yodan.

Key word: Motor Ability, Karate

\section{BAB I}

\section{PENDAHULUAN}

\section{A. Latar Belakang Masalah}

Olahraga adalah suatu aktivitas yang banyak dilakukan oleh masyarakat, keberadaannya sekarang ini tidak lagi dipandang sebelah mata tetapi sudah menjadi bagian dari kehidupan masyarakat. Sebab olahraga dewasa ini sudah tren di masyarakat baik orang tua, remaja maupun anak-anak. Karena olahraga ini mempunyai makna tidak hanya untuk kesehatan, tetapi lebih dari itu yaitu sebagai sarana pendidikan bahkan prestasi.

Berbagai cabang olahraga yang telah berkembang luas dan pesat ditengah-tengah masyarakat seperti sepak bola, bola voli, bola basket, bulu tangkis, sepak takraw, tenis lapangan, dan berbagai macam cabang olahraga permainan. Sedangkan olahraga yang bersifat berladiri juga sudah sangat berkembang di Indonesia seperti pencak silat, tarung derajat, wushu, karate, dan tae kwon do.

Cabang olahraga beladiri, khususnya karate berasal dari jepang menurut T. Chandra dalam kamus bahasa Jepang - Indonesia (Evergreen Japanese Course) Jakarta 2002 dalam Wahid (2007:5) karate berasal dari dua kata yaitu "kara" dan "te" yang secara harfiah kara berarti kosong sedangkan te berarti tangan, jika digabungkan akan membentuk kata "tangan kosong". Jadi karate dapat diartikan menjadi olahraga bela diri dengan tangan kosong yang memaksimalkan gerakan seluruh tubuh untuk melakukan pembelaan dalam bentuk hindaran (tangkisan) maupun melakukan serangan.

Jadi karate adalah salah satu olahraga beladiri tangan kosong sehingga didalam latihanlatihan teknik lebih cendrung menggunakan tangan dari pada kaki, dalam pengunaan tangan untuk memukul dan menangkis dengan prinsip satu kali serangan membuat lawan tidak mampu lagi untuk memberikan perlawanan. Dalam memenuhi hal tersebut sangat dibutuhkan sekali pembinaan prestasi yang matang baik fisik dan mental.

Pembinaan prestasi dalam karate saat ini sudah sangat baik karena olahraga karate sudah mendunia, kejuaran-kejuaran mulai dari tingkat kecamatan, kota, provinsi, nasional, dan sampai dunia sudah rutin digelar. Sehingga latihan-latihan yang dilakukan di tempat latihan sudah memiliki tujuan yang pasti dalam pembinaan berkelanjutan, disini sangat dibutuhkan peran kepemimpinan organisasi untuk memberikan peluang kepada pelatihan dan karateka agar dapat berprestasi lebih baik dan mengembangkan potensi dirinya. Hal ini tidak luput dari manajemen yang matang untuk memberikan evaluasi terhadap prestasi yang telah diraih dan yang akan diraih oleh karatekakarateka.

Melihat hal tersebut dalam UU SKN (Sistem Keolahragaan Nasional) BAB I Ketentuan Umum Pasal 1 ayat 8 telah disebutkan bahwa "Pembina olahraga adalah orang yang memiliki minat dan pengetahuan, 
kepemimpinan, kemampuan manajerial, dan pendanaan yang didedikasikan untuk kepentingan pembinaan dan pengembangan olahraga". Hal ini sejalan dengan berbagai tujuan dan sasaran kegiatan olahraga karate seperti pembinaan prestasi di perlukan usaha yang secara sistematis dan dalam waktu yang relatif lama, latihan karate yang menggunakan waktu kurang lebih 2 sampai 8 tahun berlatih dan ini penulis rasakan merupakan waktu yang cukup realistis dalam mencapai prestasi yang tinggi, intinya pembinaan prestasi dilakukan sejak usia muda.

Untuk dapat meraih prestasi tinggi dalam karate dan menguasai keterampilan kata dan kumite dalam karate tidak terjadi secara sekejap saja, melainkan melalui proses dan tahapan latihan dalam karate terdapat tiga aspek yang penting dalam tahapan latihan yang merupakan karakteristik dari olahraga karate tersebut yaitu latihan kihon, komite dan kata. Menurut Nakayama dalam Wahid (2007:75) menyatakan bahwa;

"Kihon merupakan fundamen dasar gerakan karate, latihan dasar karate yang terdiri dari teknik tangkisan, pukulan dan tendangan, Kumite adalah pertarungan dua orang yang saling berhadapan dan menampilkan teknikteknik dan Kata adalah jurus yang merupakan perpaduan dari semua teknik dasar yaitu tangkisan, tinjuan, sentakan atau hentakan dan tendangan yang dirangkai sedemikian rupa dalam satu kesatuan dalam bentuk yang pasti”.
Dari tiga karakteristik terebut kata sebagai penentu baik ataupun buruk hasil latihan karateka selama ini, tampilan kata secara automatis menentukan kualitas dari kihon yang mereka latih selama. Hal ini sejalan dengan kutipan diatas bahwa kata yang diartikan perpaduan semua teknik dasar (kihon). Berbicara tentang teknik dasar sama hal kita membicara kemampuan gerak dilakukan oleh setiap karateka, teknik dasar sangat bergantung dari aktivitas fisik yang lakukan sehari-hari dengan kondisi tubuh yang sudah aktif tentunya komponen kemampuan gerak (motor ability) juga otomatis meningkat.

Kemampuan gerak dalam proses, penulis melihat secara realitas masih banyak karateka melakukan gerak kihon masih dalam keraguan sehingga gerak yang ditampil telihat kaku dan terhambat, karateka hanya memperhatikan gerak yang diperaga oleh pelatih dan melakukan gerakan tersebut sesuai instruksi. Setalah berlatih gerakan-gerakan dasar (kihon) barulah karateka diberikan pengenal kata.

Setiap kata memiliki karakter berbeda, kata shitei terdiri dari beberapa kata yang diberi nama heian yang memiliki karakter yang sangat keras, harmonis, dan bertenaga. Menurut Wahid (2007:77) Kata Heian berarti "Heian adalah Pikiran penuh kedamaian". Kata heian pada shutokan karate-do aliran dalam WKF (World Karate Federation) ada lima tingkatan kata yang harus dikuasai oleh karateka, masing-masing kata tersebut harus dilatih satu persatu berdasarkan tingkatan sabuk menurut Danardono 
(2010:3) menyatakan adapun jenis Kata heian yaitu:

Heian Shodan, Heian Nidan, Heian Sandan, Heian Yondan, Dan Heian Godan. Pada setiap kata, terdiri dari bebrapaa gerakan. Heian shodan (kata 1) terdiri dari 21 gerakan. Heian Nidan (kata 2) terdiri dari 27 gerakan, Heian Sandan (kata 3) terdiri dari 25 gerakan, Heian Yondan (kata 4) terdiri dari 28 gerakan dan Heian Godan (kata 5) terdiri dari 27 gerakan.

Seluruh kata heian diatas dijadi materi latihan berdasarkan tingkatan sabuk seperti; sabuk putih mereka harus menguasai kata heian sondan dikenal dengan kata 1, sabuk kuning mereka akan diberikan latihan kata heian nindan dikenal dengan kata 2, setelah sabuk hijau kata 3, biru kata 4, dan coklat kata 5. Seluruh kata heian yang ditampilkan sudah baku dan tetap dengan penilaian yang telah ditentukan oleh WKF mulai dari tingkat kota, daerah, nasional, asean, asia dan internasional menampilkan dan memainkan kata yang sama. Penilai ini tidak terbatas pada kata saja akan tetapi kumite juga menggunakan peraturan WKF.

Di dalam kata heian ada gerak cepat dan gerak lambat, dimana perpindahan dari gerak lambat ke gerakan cepat harus dijaga keseimbangan. Bentuknya berubah-ubah mengikuti irama dari setiap teknik, ada saatnya pengerahan tenaga dengan kontrol pernapasan dan pada kesempatan yang tepat tiba-tiba dilontarkan tenaga yang dipusat pada satu titik dikenal dengan daya ledak.
Dalam melakukan Kata kondisi mental karateka bisa mempengaruhi keberhasilannya. Salah satunya adalah konsentrasi pemain, tingkat konsentrasi karateka juga sangat mempengaruhi dengan keberhasilan melakukan kata. Seorang karateka yang memiliki tingkat konsentrasi yang tinggi biasanya berbeda dengan karateka yang susah berkonsentrasi dalam melakukan kata Konsentrasi adalah pemusatan pemikiran kepada suatu objek tertentu. Priambodo, dalam Wicaksono (2013:44). "Konsentrasi merupakan hal yang penting dalam aktivitas hidup".

Aktifitas seseorang bisa dilakukan dengan baik jika orang tersebut memiliki tingkat konsentrasi yang tinggi. Karena dalam kehidupan ini berbagai aktifitas yang harus dilakukan sangat kompleks, begitupun dalam aktifitas olahraga, kemampuan konsentrasi sangat membantu karateka dalam menampilkan berbagai keterampilannya khususnya dalam menghadapi berbagai pertandingan.

Dojo Angkasa Lanud Padang adalah salah satu Dojo Lemkari (Lembaga Karate-DO Indonesia) yang beraliran shutokan Karate yang ada di Kota Padang, karateka yang dojo ini terdiri dari siswa-siswi SMP Angkasa Lanud Padang dan juga masyarakat umum. Karateka pada Dojo Lemkari Angkasa Lanud Padang memiliki berbagai macam prestasi dimana dahulu sempat memiliki prestasi yang cukup membanggakan karateka yang beprestasi pada kategori Kata dan kumite.

Berdasarkan pencermatan dan tinjauan yang peneliti lakukan di Dojo Lemkari Karate 
Angkasa Lanud Padang kedua terlihat bahwa sebagian besar karateka masih memiliki penguasaan kata yang kurang baik dalam menampilkan teknik kihon yang terdapat dalam kata. Peneliti memperhatikan pada saat karateka melakukan gerakan kata masih banyak karateka tidak menempatkan komponen kondisi fisik dalam gerak sehingga gerakan yang mereka lakukan terlihat kaku dan tersendat-sendat apalagi gerak yang bersifat kontinyu.

Adapun komponen kondisi fisik yang penulis cermati saat karateka dalam menampilkan kata adalah komponen power otot tungkai, power lengan, kelincahan, koordinasi mata, dan kecepatan. Hal ini juga di perjelas oleh pelatih Dojo Angkasa Lanud Padang Drs. Safwan, M.Pd yang menjelaskan bahwa karateka masih mengalami kesulitan melakukan gerakan dengan bertenaga, cepat, luas, fokus, dan lincah dan tidak memiliki seni bermain yang disesuai dengan aturan berlaku serta sering gerakan yang dilakukan itu salah atau tidak terlaksana dengan sebagaimana mestinya.

Sehingga dari observasi tersebut peneliti menduga banyak faktor yang mempengaruhi dalam menampilkan kata. Berkaitan dengan keadaan kondisi fisik karateka peneliti merasa perlu dikembangkan dalam bentuk latihan-latihan kondisi fisik dalam bentuk sirkuit yang terdiri beberapa komponen kondisi fisik dalam satu kali pelaksanaan latihan seperti zig-zag run digabungkan dengan lempar tangkap bola, tarik-menarik dengan lompat kodok, melempar bola sejauh mugkin dengan langsung mengejar bola yang telah dilempar tersebut dan masih banyak lagi jenis latihan fisik yang dapat membatu karateka dalam beradaptasi dengan kondisi fisik yang dibutuh dalam penguasaan kata heian yodan tersebut.

Dari pandangan diatas penulis menduga ada dua faktor secara umum yang berhubungan yaitu faktor internal dan eksternal, faktor secara internal diantaranya adalah minat, persepsi, kognitif, motivasi, gizi, dan afektif. Secara eksternalnya sangat banyak faktor yang mempengaruhi diantaranya, penguasaan teknik dasar (Kihon), rutinitas, ekonomi, dukungan orang tua, kopetensi pelatih, dan kondisi fisik. Faktor-faktor tersebut sangat besar hubungan dan kontribusinya dalam penguasaan Kata.

Sehingga secara garis besar faktor utama dalam sebuah penguasaan gerakan dalam kata adalah kognitif, kondisi fisik, teknik, lisensi pelatih, dan gizi. Salah satu faktor ekternal adalah kemampuan fisik yang berhubungan dengan kemampuan gerak (motor ability) yang mempengaruhi penampilan kihon yang telah dirangkai pada kata baik dalam latihan maupun dalam pertandingan.

Dalam penelitian nantinya dari lima kata heian yang ada penulis hanya melihat pada kata heian yodan saja. Kata heian yodan adalah kata ke 4 yang memiliki jumlah gerak sebanyak 28 gerak, dalam menampilkan kata ini karateka bisa menggunakan waktu 50 detik sampai 1 (satu) menit dalam satu kali tampil sedangkan dalam satu pertandingan karateka bisa 
menampilkan kata 5 sampai 8 kali main dalam waktu 5 - 10 menit.

Kata heian yodan tergolong pada kata dasar (Shitei kata) yang biasa dimain untuk kelas kadet dan pemula yang berumur antara 5 smpai 15 tahun. Namun untuk pemula karateka harus juga menguasai tukui kata minimal 2 buah kata untuk ditampilkan pada babak semi final dan final. Unsur-unsur dasar kemampuan gerak yang dinamis dan mudah dikerjakan adalah daya ledak lengan dan tungkai, kecepatan, kelincahan, dan koordinasi.

Terkait dengan hal tersebut maka unsur kemampuan gerak (motor ability) dan konsentrasi secara praktis sebuah tuntutan utama dalam penguasaan kata heian yodan suatu teknik dikaitkan dengan kesempurnaan gerakan yang ditampilkan dalam menampilkan kata heian yodan di dukung dengan kondisi fisik yang baik pula. Berdasarkan uraian observasi dan faktorfaktor yang telah dikemukakan di atas maka penulis tertarik untuk melakukan penelitian mengenai kontribusi motor ability dan konsentrasi terhadap kata heian yodan pada cabang olahraga karate.

Adapun teknik-teknik dasar yang terdapat dalam Kata heian yodanyang terdiri dari beragai jenis pukulan, tangkisan, dan tendangan dalam melakukan masing-masing gerak dasar tersebut disokong dengan adanya kuda-kuda agar gerakan itu lebih kokoh bentuk dan memiliki arti dalam memperagakannya, diantara teknik-teknik dasar tersebut adalah sebagai berikut;

\section{1) Gedan Juji Uke}

Tangkisan menggunakan dua tangan bersilang, telapak tangan dapat berbentuk seiken atau shuto. Kalau dalam bentuk shuto karateka dapat langsung memegang atau mengait serangan lawan

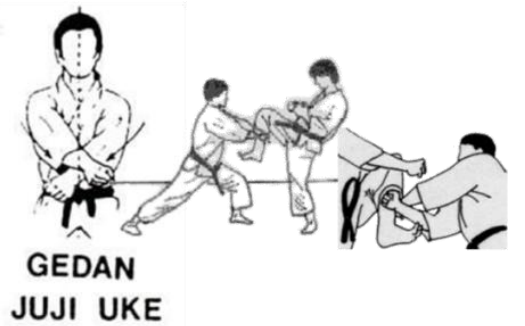

Gambar 1: Gedan Juji Uke Sumber: Sujoto (2006:51)

\section{2) Chudan Morote Uke}

Kepalan dilontarkan dari sisi dada dan disodokan ke daerah perut, posisi kepalan tetap menghadap ke atas

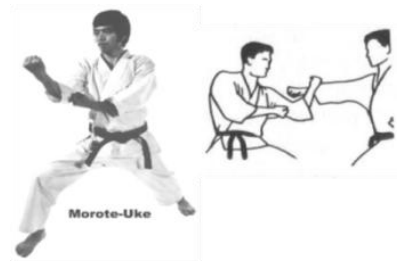

Gambar 2. Chudan Morote Uke Sumber: Sujoto (2006:25)

\section{3) Uraken Uchi}

Letakan kedua kepalan tanggan setinggi perut, lontarkan ke samping daerah limpa kecil bengkokkan pergelangan tangan pada saat kontak dan segera tarik kembali.

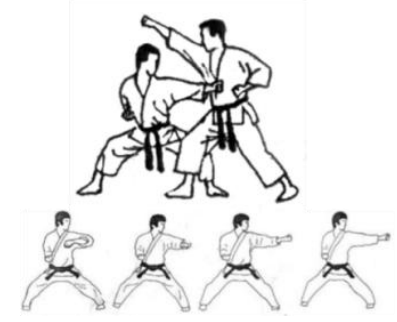

Gambar 3. Uraken Uchi 
4) Mae Enpi

Sumber: Sujoto (2006:35)

Arahkan siku ke samping, posisi siku dilipat dan dibawa ke samping kiri kemudian dilontarkan ke samping kanan. Posisi kepalan ada di sisi dada, sehingga sudut siku tetap rapat pada saat melontarkan siku jangan terbuka.

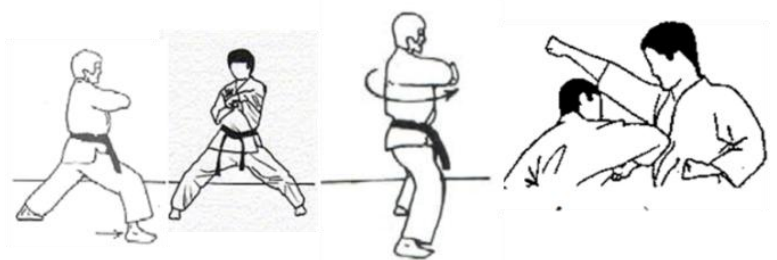

Gambar 4. Mae Enpi

Sumber: Sujoto (2006:36)

5) shuto uchi

Tangan pisau dilontarkan dari belakang telinga melingkar ke arah pelipis, kepala, atau leher lawan, tangan berhenti pada saat kontak dengan sasaran. Tangan tarikan diletakkan di sisi dada.

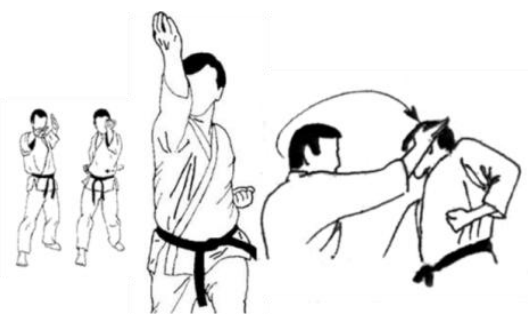

Gambar 5. Shuto Uchi

Sumber: Sujoto (2006:41)

\section{6) Chudan Uraken Uchi}

Kedua kepalan diletakan setinggi dada, lontarkan pukulan ke arah samping atas segera tarik kembali setelah kontak. Posisi pergelangan tangan diketuk pada saat kontak. Lihat gambar berikut ini;

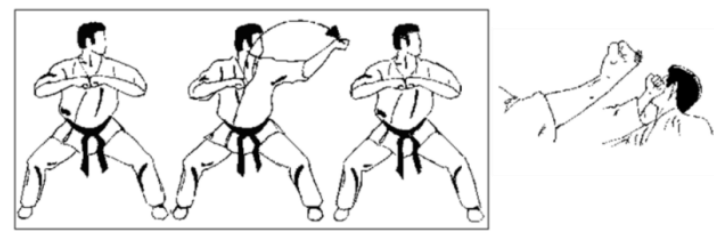

Gambar 6. Chudan Uraken Uchi Sumber: Sujoto (2006:35)

7) Chudan Oi Zuki

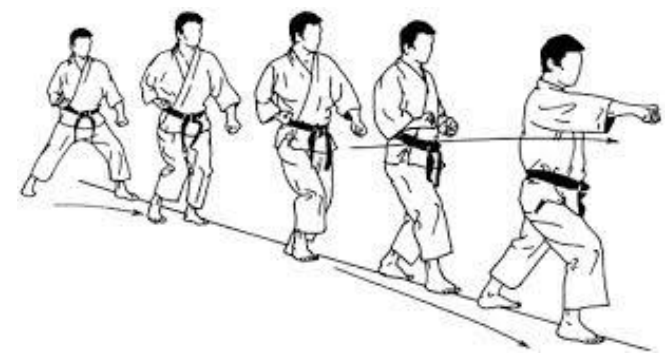

Gambar 7. Chudan Oi Zuki Sumber: Hamid (2007:35)

8) chudan gyaku zuki

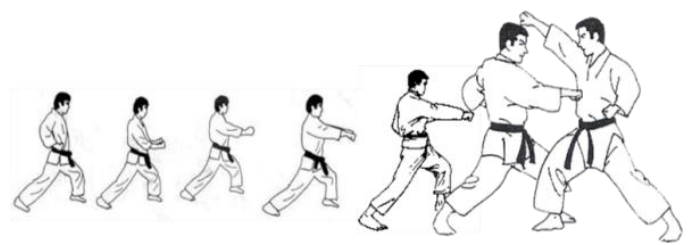

Gambar 8. Chudan Gyaku zuki

Sumber: Hamid (2007:35)

9) Morote Kubi Osae

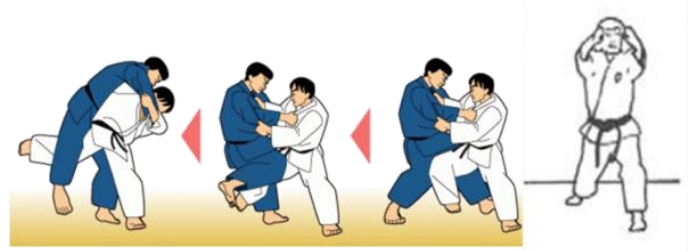

Gambar 9. Morete Kubi Osae

Sumber: Roth (2000:137)

10) chudan shuto uke. 


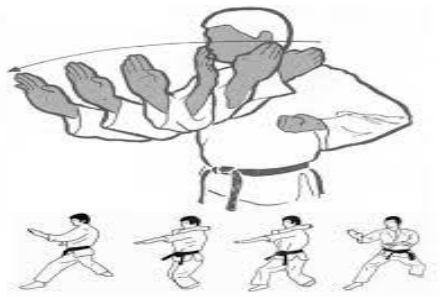

Gambar 10. Shuto-Uke (Tangkisan

Pedang)Sumber: Roth (2000:95)

Seluruh gerakan tersebut harus dilakukan dengan power atau daya ledak selain unsur kekuatan terdapat unsur kecepatan berkaitan dengan otot lengan, kemampuan yang harus dimiliki disini adalah kekuatan otot tangan dan kecepatan otot tangan. Karateka harus mengetahui kapan gerakan itu harus dilakukan dengan lambat, gerakan tersebut dilakukan dengan tiba dan gerakan tersebut harus dilakukan dengan tenaga maksimal baik melalui pukulan ataupun tangkisan. Penekanan-penekanan terhadap masing-masing gerakan tersebut tidak mudah untuk mendepatkan agar kesesuai antara kecepatan dan kekuatan bisa sejalan.

\section{B. METODOLOGI PENELITIAN}

Jenis penelitian yang digunakan adalah Korelasional. Menurut Hadeli dalam Riko (2015:47) "Corelational Research adalah penelitian yang dimaksud melihat hubungan antara dua variabel atau lebih dan biasanya menggunakan rumus statistik untuk menentukan derajat dan arah hubungan variabel tersebut. Selanjutnya melihat seberapa besar kontribusi dan variabel yang diteliti.

Penelitian ini dimaksud untuk menentukan tingkat hubungan variabel-variabel yang berbeda dalam suatu populasi dan bertujuan untuk mengetahui seberapa besar kontribusi variabel prediktor dan variabel kriteria. Adapun variabel prediktor adalah motor ability dan kosentrasi sedangkan variabel kriteria adalah penguasaan Kata Heian Yodan pada karateka Dojo Lemkari Angkasa Lanud Padang.

\section{Tempat dan Waktu Penelitian}

1. Tempat penelitian

Penelitian ini bertempat di SMP Angkasa Lanud Padang.

2. Waktu penelitian

Penelitian ini dilaksanakan pada bulan Maret - April 2016.

\section{Jenis dan Sumber Data}

1. Jenis Data

Jenis data dalam penelitian ini adalah data primer dan data sekunder.

a. Data primer

Data primer adalah data yang langsung diambil dari tes dan pengukuran sampel.

b. Data Sekunder

Data yang diperoleh dari dokumen-dokumen yang diberikan oleh pelatih karate Dojo Lemkari Angkasa Lanud Padang yang bersangkutan seperti biodata karateka, maupun data lain yang mendukung penelitian ini.

2. Sumber Data

Sumber data dalam penelitian ini adalah seluruh karateka Lemkari Dojo Angkasa Lanud Padang dan MTs Al- 
Furqan yang terpilih menjadi sampel.

\section{Populasi dan Sampel}

\section{Populasi}

Menurut Sugiyono dalam Riko (2015:49) populasi adalah "Wilayah generalisasi yang terdiri atas objek/subjek yang mempunyai kualitas atau karakteristik tertentu yang ditetapkan oleh penelitian untuk dipelajari dan kemudian ditarik kesimpulannya". Jumlah populasi dalam penelitian ini seluruh karateka dojo yang terdaftar dalam kegiatan latihan karate.

Dojo Angkasa Lanud Padang berjumlah 28 orang, terdiri dari Putra 13 orang dan Putri 15 orang sedangkan Dojo SMP Al

- Furqan berjumlah 27 orang yang terdiri dari Putra 10 orang dan Putri 17 orang, semuanya berumur $13-16$ tahun. Populasi dalam penelitian ini seluruh karateka putri yang berjumlah 32 orang.

\section{Sampel}

Teknik pengambilan sampel dalam penelitian ini di gunakan teknik purporsive sampling. Menurut Margono dalam Riko (2015:50), Teknik ini dilakukan berdasarkan pertimbangan peneliti sendiri dalam penentuan jumlah sampel. Pertimbangan yang di utamakan adalah 1) kemampuan kondisi fisik antara putera dan putri berbeda fisiologis baik secara pertumbuhan dan perkembangan fisik, 2) Jumlah karateka yang sering latihan di Dojo Angkasa Lanud Padang berdasarkan laporan Pelatih dan pengamatan penulis karateka yang hadir kebanyakan putri, 3) berdasarkan pertimbangan 1 dan 2 diduga karateka putri yang mengetahui gerakan kata heian yodan,

Sehingga penentuan jumlah sampel di fokus kepada karateka putri saja didasarkan atas pertimbangan-pertimbangan tersebut, maka penulis menetapkan sampel dalam penelitian ini adalah sebanyak 32 orang karateka.

\section{Teknik Pengumpulan Data}

Nurhasan dalam Kamaludin (2015:35) menjelaskan mengenai tes dan pengukuran yaitu: "Suatu alat yang digunakan dalam memperoleh data dari suatu objek yang akan diukur, sedangkan pengukuran merupakan suatu proses untuk memperoleh data dengan menggunakan tes, diukur dengan menggunakan Barrow Motor Ability Test yang dikutip Nurhasan dan Cholil (2007:130) dalam Kamaludin (2015:35) yaitu Barrow motor ability test yang meliputi : 1) Standing Broad Jump, 2) Soft Ball Throw 3) Zigzag Run, 4) Wall Pass, 5) Medicine Ball-Put, 6) Lari 60 yard.

\section{Instrumen Penelitian}

\section{Motor Ability Test}

Tes motor ability diukur dengan menggunakan Barrow Motor Ability Test yang dikutip Nurhasan dan Cholil (2007:130) dalam Kamaludin (2015:35) yaitu Barrow motor ability test yang meliputi : 1) Standing Broad Jump, 2) Soft Ball Throw 3) Zig-zag Run, 4) Wall Pass, 5) Medicine Ball-Put, 6) Lari 60 yard,

\section{Tes Kosentrasi}

Kontribusi Motor Ability Dan Konsentrasi Terhadap..... 25 Arie Asnaldi 
Salah satu latihan untuk mengukur kemampuan fokus adalah dengan menggunakan latihan Grid Concentration Test. latihan ini memiliki 10 x 10 kotak yang setiap kotak berisi 2 digit angka mulai 00 sampai 99. tujuan dari latihan ini adalah untuk menghubungkan angka dengan garis di mulai dengan angka 00 sampai 99 selama 1 menit. Penilaian diambil dari angka tertinggi yang bisa di capai.

\section{Teknik Analisa Data}

Teknik analisis data yang digunakan adalah analisis korelasi sederhana dan ganda. Hipotesis pertama dan hipotesis kedua dianalisis dengan korelasi, sedangkan hipotesis ketiga dianalisis dengan korelasi ganda.

Sebelum melakukan analisis terhadap data di atas, dilakukan uji persyaratan, yaitu:

1. Uji normalitas untuk mengetahui apakah data berasal dari populasi yang berdistribusi normal, dilakukan dengan uji liliefors.

2. Uji Homogenitas instrumen.

3. Uji independensi antar prediktor untuk mengetahui apakah ada kontaminasi antara variabel bebas dalam hubungannya dengan variabel terikat menggunakan rumus: $t=\frac{r \sqrt{\boldsymbol{n}-2}}{1-r^{2}}$

4. Untuk melihat besarnya Hubungan Motor Ability dan konsentrasi terhadap
Penguasaan kata heian yodan digunakan teknik korelasi $r$ Pearson dengan rumus sebagai berikut:

$$
\begin{aligned}
& r_{x y} \\
& =\frac{n \sum X \boldsymbol{Y}-\left(\sum X\right)\left(\sum \boldsymbol{Y}\right)}{\sqrt{\left\{n \sum X^{2}-\left(\sum X\right)^{2}\right\}}\left\{n \sum Y^{2}-\left(\sum \boldsymbol{Y}\right)^{2}\right\}}
\end{aligned}
$$

\section{Hipotesis Statistika}

Berdasarkan hipotesis yang diajukan pada bab II, maka bentuk hipotesis statistik yang akan diuji dalam pelitian ini dapat dirumuskan sebagai berkut:

(1) Ho : $\rho_{\text {y. } 1} \leq 0$

$$
\mathrm{H}_{1}: \rho_{\mathrm{y} .1}>0
$$

(2) Ho : $\rho_{\text {y. } 2} \leq 0$

$$
\mathrm{H}_{1}: \rho_{\mathrm{y} .2}>0
$$

(3) Ho : $\rho_{\text {y. } 123} \leq 0$

$$
\mathrm{H}_{1}: \rho_{\mathrm{y} .12}>0
$$

Keterangan :

Ho : Hipotesis no

$\mathrm{H}_{1} \quad$ : Hipotesis alternatif

$\rho_{\text {y1 }} \quad$ : Koefisien korelasi antara Motor Ability $\left(\mathrm{X}_{1}\right)$ dengan Penguasaan Kata Heian Yodan (Y)

$$
\begin{array}{cclr}
\rho_{\mathrm{y} 2} & : \quad \text { Koefisien } & \text { korelasi } & \text { antara } \\
& \text { Konsentrasi } & \left(\mathrm{X}_{2}\right) & \text { dengan } \\
& \text { Penguasaan } & &
\end{array}
$$

\section{Kata Heian Yodan (Y)}

$\rho_{\text {yx12 }} \quad$ Koefisien korelasi antara Motor Ability $\left(\mathrm{X}_{1}\right)$, dan Konsentrasi $\left(\mathrm{X}_{2}\right)$

dengan Penguasaan Kata Heian Yodan $(\mathrm{Y})$ 
6. Rumus Koefisien Determinasi

Untuk melihat besarnya kontribusi dilihat dengan koefisien korelasi, seperti rumus ini $(\mathrm{rx} 100 \%) \cdot \mathrm{K}=\mathrm{r}^{2} \mathrm{X} 100 \%$.

\section{PEMBAHASAN}

Pengolahan dan analisis dilakukan untuk mengetahui kontribusi motor ability dan konsentrasi terhadap penguasaan kata heian yodan. Uji statistik yang digunakan adalah uji regresi pada taraf signifikansi $\alpha 0.05$. Untuk lebih jelasnya akan disajikan secara berurutan sebagai berikut:

\section{Terdapat Kontribusi Motor Ability Terhadap Penguasaan Kata Heian Yodan Karateka Putri Dojo Angkasa Lanud Padang.}

Hasil analisis menunjukkan bahwa motor ability $\left(\mathrm{X}_{1}\right)$ memiliki hubungan yang signifikan serta memberikan kontribusi yang berarti terhadap penguasaan kata heian yodan. Nilai persamaan regresi dapat digambarkan sebagai berikut; $\hat{\mathrm{Y}}=8,41+0,28 \mathrm{x}$ dengan $\mathrm{f}_{\text {hitung }} 1.57<\mathrm{f}_{\text {tabel }}$ 2.80. Pada tabel analisis korelasi data penelitian diperoleh korelasi motor ability terhadap penguasaan kata heian yodan sebesar $\mathrm{r}_{\mathrm{x} 1 \mathrm{y}}=0.405$ dengan $\mathrm{t}_{\text {hitung }}=2,344>\mathrm{t}_{\text {tabel }} 1.701$ menyatakan bahwa terdapat hubungan yang signifikan antar kedua variabel. Hal ini menyatakan data dalam keadaan linear. Dengan demikian hipotesis yang diajukan (Ha) dapat diterima.

Cabang olahraga memerlukan motor ability untuk melakukan aktifitas yang baik. Dalam beberapa cabang olahraga seperti bola volly, atletik, tenis, karate, tinju, taekwondo dan lain-lain merupakan kegiatan yang membutuhkan motor ability yang baik. Motor ability atau kemampuan gerak mempunyai peranan penting di dalam kehidupan sehari-hari maupun di dalam latihan karate. Pengetahuan ini berguna untuk menjadi arah perkiraan apakah seorang karateka yang akan diteliti memungkinkan untuk tumbuh dan berkembang menjadi individu yang memiliki jiwa olahragawan dan berprestasi.

Berdasarkan urian di atas sesuai dengan pendapat Syahara (2011:67) “ seiring dengan perkembangan karateristik fisik tertentu serta kedewasaan fisiknya, maka akan berkembang pula kemampuan si anak untuk melakukan keterampilan motoriknya". Dilihat dari taksonomi gerak umum, kata bisa secara lengkap diwakili oleh gerak-gerak dasar yang membangun pola gerak yang lengkap, dari mulai pola gerak lokomotor, nonlokomotor, sekaligus manipulatif.

\section{Terdapat Kontribusi Konsentrasi Terhadap Penguasaan kata heian yodan karateka Putri Lemkari Dojo Angkasa Lanud Padang.}

Hasil analisis menunjukkan bahwa konsentrasi $\left(\mathrm{X}_{2}\right)$ memiliki hubungan yang signifikan serta memberikan kontribusi yang 
berarti terhadap hasil penguasaan kata heian yodan. Nilai persamaan regresi dapat digambarkan sebagai berikut $\hat{Y}=12,24+0,77 x$ dengan $\mathrm{F}_{\text {hitung }} 2,83<\mathrm{f}_{\text {tabel }}$ 2,64. Pada tabel analisis korelasi konsentrasi terhadap penguasaan kata heian yodan sebesar $r_{\mathrm{x} 2 \mathrm{y}}=0,517$ dengan $t_{\text {hitung }}=3,195>t_{\text {tabel }} 1,701$ menyatakan bahwa terdapat hubungan yang signifikan antar kedua variabel. Hal ini menyatakan data dalam keadaan linear. Dengan demikian hipotesis yang diajukan (Ha) dapat diterima.

Konsentrasi merupakan bagian penting dalam aktivitas hidup. Aktivitas seseorang bisa dilakukan dengan baik jika orang tersebut memiliki kemampuan konsentrasi yang tinggi. Karena dalam kehidupan ini, berbagai aktivitas yang harus dilakukan sangat komplek, begitupun dalam aktivitas olahraga, kemampuan konsentrasi sangat membantu atlet dalam menampilkan berbagai keterampilannya khususnya dalam menampilkan kata heian yodan.

Konsentrasi sangat dibutuhkan terutama untuk cabang olahraga yang menuntut konsentrasi tinggi seperti panahan, menembak, karate dan olahraga catur. Sebab olahraga karate menuntut ketepatan, ketelitian, konsistensi, dan setiap tindakan dari setiap gerakan yang dilakukan. Dalam penelitian ini peneliti memaparkan konsentrasi kemampuan untuk memusatkan perhatian pada tugas dengan tidak terganggu dan terpengaruhi oleh stimuli yang bersifat eksternal maupun internal, selanjutnya konsentrasi sebagai perubahan yang konstan yang berhubungan dengan dua dimensi yaitu dimensi luas (width) dan dimensi pemusatan (focus).

\section{Terdapat Kontribusi Motor Ability dan Konsentrasi secara Bersama-sama terhadap Penguasaan Kata Heian Yodan Karateka Putri Lemkari Dojo Angkasa Lanud Padang.}

Analisis kedua variabel $\left(\mathrm{X}_{1}\right.$ dan $\left.\mathrm{X}_{2}\right)$ menunjukkan bahwa variabel motor ability dan variabel konsentrasi secara bersama-sama memiliki hubungan yang signifikan serta memberikan kontribusi yang berarti terhadap penguasaan kata heian yodan. Pada tabel korelasi analisis diperoleh koofesien korelasi variabel motor ability dan konsentrasi terhadap penguasaan kata heian yodan dengan harga koofisien regresi $\hat{Y}=6,15+0,16 X_{1}+0,63 X_{2}$.

Ini menunjukkan hubungan yang signifikan antara motor ability $\left(\mathrm{X}_{1}\right)$ dan kosentrasi $\left(\mathrm{X}_{2}\right)$ terhadap penguasaan kata heian yodan berarti (nyata). Dengan hipotesis yang diajukan (Ha) dapat diterima.

\section{Kesimpulan}

Kemampuan motorik merupakan modal dasar untuk keterampilan fisik yang dibutuhkan dalam kegiatan serta aktifitas olah raga bisa dipelajari dan dilatih di masa-masa awal perkembangan. Sangat penting untuk mempelajari keterampilan ini dengan suasana yang menyenangkan, tidak berkompetisi agar anak-anak mempelajari olah raga dengan senang dan merasa nyaman untuk ikut berpartisipasi. 
Proses belajar gerak berbentuk kegiatan mengamati gerakan dan kemudian mencoba menirukan berulang-ulang, dan menerapkan pola-pola gerak tertentu pada situasi tertentu yang dihadapi, dan juga dalam bentuk menciptakan pola-pola gerak baru untuk tujuantujuan tertentu. Dalam belajar gerak karateka harus memahami gerakan untuk mampu melakukannya, maka selain unsur fisik disitu juga terlibat unsur fikir.

Unsur konsentrasi dan perasaan juga terlibat dalam belajar gerak, karena konsentrasi dan perasaan merupakan unsur psikis yang merupakan daya penggerak dalam berprilaku. Seseorang akan melakukan gerakan tertentu apabila mempunyai kemauan untuk bergerak dan merasa perlu untuk melakukan gerakan. Dalam melakukan suatu gerakan apabila ia tahu atau mengerti gerak apa yang harus dilakukan, dan gerakan tertentu itu akan terwujud apabila ia memiliki cukup kemampuan untuk bergerak.

\section{DAFTAR RUJUKAN}

Aryati Nuryana dan Setiyo Purwanto. 2010. "Efektivitas Brain Gym dalam meningkatkan Konsentrasi belajar pada anak". Indigenous, Jurnal Ilmiah Berkala Psikologi. Vol. 12, No. 1, Mei $2010: 88-99$

Danardono. "Ujian DAN INKAI". Makalah disajikan dalam seminar Penataran/Lokakarya. Jakarta. Tanggal 4 - 5 Desember 2010

Fauzi, Ahmad. 2010. "Pengaruh Pendekatan Pembelajaran dan Kemampuan Gerak terhadap Hasil Belajar Keterampilan Menggiring Bola pada Permainan
Sepakbola". Tesis tidak diterbitkan. Surakarta. Program Studi Ilmu Keolahragaan, Program Pascasarjana Universiras Sebelas Maret.

Hamid, Apris. 2007. Teknik Dasar Karate (Kihon). Padang: Inkanas Sumatera Barat.

Harmono, Bayu. Akbar. 2014. Kontribusi Konsentrasi Terhadap Ketepatan Pukulan Jumping Smash pada Bulutangkis. Jurnal Kesehatan Olahraga. Volume 02 Nomor 01.

Kamaludin, Septian. 2015. "Hubungan motor ability dengan hasil pemanjatan panjat dinding kategori rintisan ( $L E A D$ )'” Universitas Pendidikan Indonesia. repository.upi.edu. perpustakaan.upi.edu

Kiram, Yanura. 2010. Belajar Motorik Lanjutan. Padang: Sukabina

Lutah, Rusli. 1988. Belajar Keterampilan Motorik Pengantar Teori dan Metode. Jakarta. Depdikbud. DIKTI. Proyek Pengembangan Lembaga Pendidikan Tenaga Kependidikan

Nurdin. 2009. "Pengaruh Metode Pembelajaran dan Kemampuan Gerak Dasar Terhadap Keterampilan Servis Bola Voli". Tesis tidak diterbitkan. Surakarta. Program Studi Ilmu Keolahragaan, Program Pascasarjana Universiras Sebelas Maret.

Panduan Pertandingan Federasi Karate

Tradisional Indonesia-INKAI. Jakarta.

HaKI HCI. 023382 18-02-2002

PUSDIKKU TNI AD. (2001). "Sertifikasi Pelatih Karate Tingkat Nasional I/Utama”. Seminar/Lokakarya. Bandung, 16 Maret - 29 Maret. 